\title{
Economic co-production of poly(malic acid) and pullulan from Jerusalem artichoke tuber by Aureobasidium pullulans HA-4D
}

\author{
Jun Xia ${ }^{1 *}$, Jiaxing $X u^{1}$, Xiaoyan Liu', Jiming $X u^{1}$, Xingfeng $W^{1}{ }^{1}$ and Xiangqian $L^{2}$
}

\begin{abstract}
Background: poly(L-malic acid) (PMA) is a water-soluble polyester with many attractive properties in medicine and food industries, but the high cost of PMA fermentation has restricted its further application for large-scale production. To overcome this problem, PMA production from Jerusalem artichoke tubers was successfully performed. Additionally, a valuable exopolysaccharide, pullulan, was co-produced with PMA by Aureobasidum pullulans HA-4D.

Results: The Jerusalem artichoke medium for PMA and pullulan co-production contained only $100 \mathrm{~g} / \mathrm{L}$ hydrolysate sugar, $30 \mathrm{~g} / \mathrm{L} \mathrm{CaCO}_{3}$ and $1 \mathrm{~g} / \mathrm{L} \mathrm{NaNO}_{3}$. Compared with the glucose medium, the Jerusalem artichoke medium resulted in a higher PMA concentration (114.4 g/L) and a lower pullulan concentration (14.3 g/L) in a $5 \mathrm{~L}$ bioreactor. Meanwhile, the activity of pyruvate carboxylase and malate dehydrogenas was significantly increased, while the activity of a-phosphoglucose mutase, UDP-glucose pyrophosphorylase and glucosyltransferase was not affected. To assay the economic-feasibility, large-scale production in a $1 \mathrm{t}$ fermentor was performed, yielding $117.5 \mathrm{~g} / \mathrm{L}$ PMA and $15.2 \mathrm{~g} / \mathrm{L}$ pullulan.

Conclusions: In this study, an economical co-production system for PMA and pullulan from Jerusalem artichoke was developed. The medium for PMA and pullulan co-production was significantly simplified when Jerusalem artichoke tubers were used. With the simplified medium, PMA production was obviously stimulated, which would be associated with the improved activity of pyruvate carboxylase and malate dehydrogenas.
\end{abstract}

Keywords: Poly(malic acid), Pullulan, Jerusalem artichoke, Co-production, Enzyme activity

\section{Background}

$\operatorname{Poly}(\beta$-malic acid) (PMA) is a water-soluble polyester consisting of malic acid monomer. Since PMA has many attractive properties, including biocompatibility, biodegradability and can be easily chemically modified, this polyester has attracted great interest for its potential in biomedical and food applications [1, 2]. For example, Ljubimova et al. have developed a new drug delivery system based on PMA and called it Polycefins ${ }^{\mathrm{Th}}$ [3]. Polycefins $^{\mathrm{Tm}}$ was of direct tumor targeting and showed a significant decrease in the tested cancer cell viability $[4,5]$. Currently, Polycefins ${ }^{\mathrm{m}}$ is at the step of preclinical trials

\footnotetext{
*Correspondence: xiajun050219@126.com

1Jiangsu Key Laboratory for Biomass-Based Energy and Enzyme Technology, Jiangsu Collaborative Innovation Center of Regional Modern Agriculture and Environmental Protection, College of Chemistry and Chemical Engineering, Huaiyin Normal University, Huai'an 223300, China

Full list of author information is available at the end of the article
}

and is considered to be a promising candidate for anticancer treatment. On the other hand, the only monomer of PMA, malic acid, is predominantly used in the food and beverage industries as an acidulant and taste modifier [6]. Several microorganisms including Aspergillus species, Schizophyllum commune and engineered Escherichia coli are capable of producing malic acid [7, 8]. Among these microbes, A.flavus can produce malic acid at the highest titer of $113 \mathrm{~g} / \mathrm{L}$ [7]. However, A.flavus is a pathogenic microbe thus its industrial application has been prevented [9], and the production of malic acid by genetically engineered E.coli is severely limited by the end-product inhibition because of the strong acidity of malic acid [8]. By contrast, PMA is not toxic to cells, thus it can be accumulated to a high concentration in the culture broth. It was found that some strains of Aureobasidium spp. could produce large quantities of PMA under suitable conditions [2, 10], Aureobasidium spp. is nonpathogenic and 
thus it is suitable for industrial application. Therefore, microbial fermentation of PMA followed by acid hydrolysis provides a promising route for commercial malic acid production. For example, Zou et al. [2] investigated the feasibility of malic acid production derived from PMA. They found that A.pullulans ZX-10 could produce PMA as the major product at a high titer of $125.5 \mathrm{~g} / \mathrm{L}$, and pure malic acid was then obtained from acid hydrolysis of PMA with a high recovery rate of $84 \%$, this study offered an alternative method for malic acid production in the future.

The cost of microbial fermentation of PMA is high when glucose is used as the carbon source, research into employing other renewable and inexpensive feedstock for PMA production has attracted more attention. Lignocellulosic materials from agricultural by-products (e.g., corn fiber and wheat straw) are considered as primary carbon sources for biorefinery engineering, but the pretreatment of these materials is energy-consuming, and due to the low concentration of sugar and the existence of toxic compounds (furfural, 5-hydroxymethyl furfural, etc.) in the hydrolysate of these materials, only a relatively low concentration of PMA $(20 \sim 30 \mathrm{~g} / \mathrm{L})$ was obtained from these agricultural biomass [11, 12]. Sweet potato is rich in starch, which can be hydrolyzed to glucose and used by the microorganisms in the fermentation process. Zan et al. [13] performed PMA production from sweet potato hydrolysate, the maximum concentration of PMA reached $57.5 \mathrm{~g} / \mathrm{L}$ when the cells were immobilized in an aerobic fibrous-bed bioreactor. However, sweet potato is a staple food crop in parts of Africa, Asia and the Pacific [14], the large-scale production of PMA from sweet potato may create competition with humans for food. To overcome the aforementioned problems, the utilization of a nongrain crop containing a high level of carbohydrates for PMA production is necessary.

Jerusalem artichoke (Helianthus tuberosus L.) is a lowcost and widely available non-grain crop, this species does not interfere with food crop production because it can grow well in barren lands, giving a yield of about $90 \mathrm{t} /$ ha by fresh weight. Jerusalem artichoke tuber is rich in carbohydrates, of which $70-90 \%(\mathrm{w} / \mathrm{w})$ is inulin [14], and inulin can be easily hydrolyzed to monomeric sugars (fructose and glucose) for microbial fermentation. Thus Jerusalem artichoke is a promising raw material for biorefinery engineering [15]. To date, Jerusalem artichoke has been employed for the production of several biochemical products, such as 2,3-butanediol, docosahexaenoic acid and succinic acid [16-18]. Therefore, Jerusalem artichoke may be a suitable feedstock instead of glucose for microbial fermentation of PMA.

In addition to the utilization of low-cost raw materials, enriching the diversity of the products is also useful to make the fermentation more economical. Recent research showed that some PMA-producing strains could produce pullulan as a by-product $[19,20]$. Pullulan is a linear homopolysaccharide which is made mainly of maltotriose repeating units interconnected by $\alpha-1,6$ linkages [21]. This polysaccharide is of economic importance and has been commercially produced by the Hayashibara Company (Japan) since 1959 [22]. Pullulan has been applied in extensive applications such as food, pharmaceutical and chemical industries. For example, pullulan can be used to make capsules because this polysaccharide has no mutagenic and toxicological activities. NPcaps ${ }^{\ominus}$ capsules, which are made of pullulan, have been successfully brought to commercial market and used for addressing pharmaceuticals and dietary supplements [23]. In our previous study, a high PMA-producing strain, A.pullulan HA-4D, was isolated and a high production of PMA was obtained with this strain [24]. We found that strain HA-4D could also produce an unknown exopolysaccharide as a by-product, which was probably pullulan according to the literature. In the present study, an economical co-production system for PMA and pullulan from Jerusalem artichoke was developed. PMA production was obviously stimulated with the use of Jerusalem artichoke tuber hydrolysate. The underlying mechanism was discussed with regard to the key enzymes activities involved in vital pathways of PMA and pullulan biosynthesis.

\section{Methods}

\section{Microorganism and medium}

A.pullulans HA-4D (CGMCC No.7.208), which can co-produce PMA and pullulan, was used in this study. A.pullulans HA-4D was maintained on potato dextrose agar slants. The composition of seed medium was $80 \mathrm{~g} / \mathrm{L}$ glucose, $1 \mathrm{~g} / \mathrm{L}$ Yeast extract, $2 \mathrm{~g} / \mathrm{L} \mathrm{NaNO}_{3}, 0.1 \mathrm{~g} / \mathrm{L}$ $\mathrm{KH}_{2} \mathrm{PO}_{4}, 0.1 \mathrm{~g} / \mathrm{L} \mathrm{MgSO}_{4}, 0.5 \mathrm{~g} / \mathrm{L} \mathrm{KCl}$ and $20 \mathrm{~g} / \mathrm{L} \mathrm{CaCO}_{3}$. The standard PMA production medium (GM medium) consisted of $100 \mathrm{~g} / \mathrm{L}$ glucose, $2 \mathrm{~g} / \mathrm{L} \mathrm{NaNO}_{3}, 0.1 \mathrm{~g} / \mathrm{L}$ $\mathrm{KH}_{2} \mathrm{PO}_{4}, 0.1 \mathrm{~g} / \mathrm{L} \mathrm{MgSO}_{4}, 0.5 \mathrm{~g} / \mathrm{L} \mathrm{KCl}, 0.1 \mathrm{~g} / \mathrm{L} \mathrm{ZnSO}$ and $30 \mathrm{~g} / \mathrm{L} \mathrm{CaCO}_{3}$. The optimized fermentation medium (JAT medium) contained $100 \mathrm{~g} / \mathrm{L}$ hydrolysate sugar (hydrolysate of Jerusalem artichoke tuber), $1 \mathrm{~g} / \mathrm{L} \mathrm{NaNO}_{3}$ and $30 \mathrm{~g} / \mathrm{L} \mathrm{CaCO}_{3}$.

\section{Preparation of the Jerusalem artichoke tuber hydrolysate} Jerusalem artichoke tubers were harvested from farms in Xuzhou, Jiangsu Province, China in December, 2015. The washed tubers were peeled, sliced and dried. The dried tubers were ground into fine powder using a crusher. Acid hydrolysis was conducted by weighing $100 \mathrm{~g}$ of fine powder into $900 \mathrm{~mL}$ of $5 \%(\mathrm{v} / \mathrm{v})$ $\mathrm{H}_{2} \mathrm{SO}_{4}$. The mixture was heated at $80{ }^{\circ} \mathrm{C}$ for $40 \mathrm{~min}$. After hydrolysis, the hydrolysate was filtered with filter paper. The $\mathrm{pH}$ of the filtrate was adjusted to 6.5 with $1 \mathrm{M}$ $\mathrm{NaOH}$. 


\section{Optimization of the medium for PMA and pullulan co-production}

The medium optimization was performed in the shakeflask scale. Shake flask fermentation was carried out at $25^{\circ} \mathrm{C}$ and $200 \mathrm{rpm}$ for 7 days. Different concentrations of nutrient elements, including $\mathrm{NaNO}_{3}, \mathrm{KH}_{2} \mathrm{PO}_{4}, \mathrm{MgSO}_{4}$, $\mathrm{KCl}, \mathrm{ZnSO}_{4}$ and $\mathrm{CaCO}_{3}$, were added to the medium for PMA and pulluan co-production, the nutrient elements that affect PMA and pullulan co-production by A.pullulans HA-4D were standardized by varying one factor at a time. The defined parameter of one experiment was followed for the succeeding experiments.

Fed-batch fermentation for PMA and pullulan co-production A.pullulans HA-4D was maintained on a potato dextrose agar slant and then transferred into a $500 \mathrm{~mL}$ flask containing $100 \mathrm{~mL}$ of the seed medium. The seed culture was aerobically incubated at $25{ }^{\circ} \mathrm{C}$ and $200 \mathrm{rpm}$ for $48 \mathrm{~h}$, then $300 \mathrm{~mL}$ of the seed culture was inoculated into $2.7 \mathrm{~L}$ of the fermentation medium in a $5 \mathrm{~L}$ stirred tank fermentor (Winpact, USA). Fermentation was performed at $25{ }^{\circ} \mathrm{C}$ under aeration at $1 \mathrm{vvm}$ with a stirring speed of $400 \mathrm{rpm}$. The $\mathrm{pH}$ of the culture broth was maintained at approximately 6.5 with the addition of $\mathrm{CaCO}_{3}$. For fed-batch fermentation from JAT medium, when the concentration of reducing sugars in the culture broth decreased to $10 \mathrm{~g} / \mathrm{L}$, the concentrated Jerusalem artichoke tuber hydrolysate (approximately $300 \mathrm{~g} / \mathrm{L}$ reducing sugars) was fed to maintain the reducing sugar at approximately $10 \mathrm{~g} / \mathrm{L}$. The feeding rate was in the range of $9 \sim 15 \mathrm{~mL} / \mathrm{h}$, and approximately $0.9 \mathrm{~L}$ of the feeding solution was added into the $5 \mathrm{~L}$ fermentor. The final volume of culture broth was about $3.5 \mathrm{~L}$ because of the losses from sampling and water evaporation. As a control, fed-batch fermentation from glucose was also carried out, the culture parameters were identical to those of JAT medium, except that the fermentation medium was GM medium and the feeding solution was composed of $300 \mathrm{~g} / \mathrm{L}$ glucose.

Fermentation in a $1 \mathrm{t}$ fermentor was carried out in Baimai Co., Ltd. (Huai'an, China). For the seed culture, five slant eggplant flasks of A.pullulans HA-4D were inoculated into a $100 \mathrm{~L}$ fermentor containing $60 \mathrm{~L}$ of the seed medium. The seed culture was incubated at $25{ }^{\circ} \mathrm{C}$ for $48 \mathrm{~h}$. Then the seed culture was transferred into a $1 \mathrm{t}$ fermentor containing $0.54 \mathrm{t}$ of the JAT medium. The aeration was $1 \mathrm{vvm}$ and the stirring speed was $250 \mathrm{rpm}$. The feeding rate was in the range of $1.8 \sim 2.3 \mathrm{~L} / \mathrm{h}$ to maintain the residual sugar at approximately $10 \mathrm{~g} / \mathrm{L}$. The other parameters were identical to those for fedbatch fermentation in a $5 \mathrm{~L}$ fermentor.

\section{Purification and characterization of pullulan}

The culture broth was centrifuged and the resulting supernatant was used for purification of exopolysaccharide and PMA. These two biopolymers were purified by the repeated ethanol precipitation [19]. The first addition of 1 volume of cold ethanol to the supernatant was to selectively purify exopolysaccharide as precipitates, the precipitated exopolysaccharide was then subjected to dialysis for structure characteristics. After the removal of the exopolysaccharide, the supernatant was added with 2 volume of ethanol, the mixture was kept at $4{ }^{\circ} \mathrm{C}$ for overnight for precipitation of PMA.

The purified exopolysaccharide was characterized by Fourier transform infrared spectroscopy (FT-IR), ${ }^{1} \mathrm{H}$ and ${ }^{13} \mathrm{C}$ nuclear magnetic resonance (NMR) spectra. FT-IR was performed on a Nicolet 560 FT-IR spectrometer (Thermo, USA) and the sample was blended with $\mathrm{KBr}$ pellet. The ${ }^{1} \mathrm{H}$ and ${ }^{13} \mathrm{C}-\mathrm{NMR}$ spectra were recorded using a Bruker AVANCE AV-400 spectrophotometer (Bruker Biospin Corp., Billerica, MA), $10 \mathrm{mg}$ of the purified exopolysaccharide was dissolved in $0.5 \mathrm{~mL}$ DMSO$\mathrm{d}_{6}$ solvent and TMS was used as an internal standard for proton NMR [25].

\section{Assay of enzyme activity}

Cells grown in fed-batch fermentation in $5 \mathrm{~L}$ fermentor at early stage $(40 \mathrm{~h})$ and later stage $(100 \mathrm{~h})$ were collected for the measurement of intracellular enzyme activity. All procedures were carried out at $4{ }^{\circ} \mathrm{C}$. The collected cells were washed twice with $0.85 \% \mathrm{NaCl}$ solution. The harvested cells were suspended in $0.2 \mathrm{M}$ phosphate buffer ( $\mathrm{pH}$ 7.0). The suspended cells were disrupted by sonication and then centrifuged at $12,000 \times g$ at $4{ }^{\circ} \mathrm{C}$ for $10 \mathrm{~min}$. The cell debris was removed by centrifugation. The supernatant was collected as the cellfree extract and used for enzyme activity determination. Reactions were initiated by adding the cell-free extract to yield a final volume of $1 \mathrm{~mL}$. The pyruvate carboxylase (PYC; EC 6.4.1.1), malate dehydrogenase (MDH; EC 1.1.1.37) and glucosyltransferase (FKS; EC 2.4.1.34) activity were assayed according to previous reports [26-28]. The $\alpha$-phosphoglucose mutase (PGM; EC 5.4.2.2) and UDP-glucose pyrophosphorylase (UDPG; EC 2.7.7.9) activity were determined with a commercial ELISA Kit (Haochen-Bio, Shanghai, China) according to the manufacturer's instructions. The total protein concentration in the crude cell extract was measured by the Bradford method, with bovine serum albumin as a standard.

\section{Analytical methods}

The concentrations of glucose and fructose in the Jerusalem artichoke tuber hydrolysate were analyzed by HPLC (Agilent 1260 series, USA), with an Aminex HPX-87P column $(300 \times 7.8 \mathrm{~mm}$; Bio-Rad, USA $)$ and a refractive index detector. HPLC analysis was performed with deionized water as the mobile phase and a flow rate 
of $0.5 \mathrm{~mL} / \mathrm{min}$ at $80{ }^{\circ} \mathrm{C}$. The total sugar of the hydrolysate and the concentration of residual sugar during fed-batch fermentation was determined using the DNS method [29]. The total nitrogen content of Jerusalem artichoke tuber hydrolysate was determined by the Kjeldahl method with a Kjeldahl apparatus SKD-800 (Peiou, Shanghai, China) following the manufacturer's instructions.

The concentration of PMA was estimated from the concentration of malic acid after hydrolysis. The fermentation broth was centrifuged and the resulting supernatant was mixed with an equal volume of $2 \mathrm{M} \mathrm{H}_{2} \mathrm{SO}_{4}$, the mixture was incubated at $90{ }^{\circ} \mathrm{C}$ for $9 \mathrm{~h}$. After neutralization of the solution, the malic acid concentration was determined by HPLC as described previously [24]. For pullulan analysis, 1 volume of ethanol was added to the supernatant and incubated at $4{ }^{\circ} \mathrm{C}$ overnight. The precipitates were centrifuged at $8000 \times g$ for $10 \mathrm{~min}$ and dried at $80^{\circ} \mathrm{C}$ to a constant weigh [19].

\section{Results}

\section{Hydrolysis of Jerusalem artichoke tubers}

The major component of Jerusalem artichoke tubers is inulin, which is composed of multiple fructose units terminated by a glucose unit. A.pullulans has a relatively low inulinase activity $(0.05 \mathrm{U} / \mathrm{mL})$, such a low activity was unsatisfactory for exopolysaccharide or PMA production [30]. Therefore, the inulin in the medium must be subjected to hydrolysis prior to fermentation. Given its strong acid strength for cleaving inulin bonds, sulphuric acid was employed for the saccharification of Jerusalem artichoke tubers. As shown in Table 1, the Jerusalem artichoke tubers used in this study contained $20.4 \pm 0.5 \mathrm{~g} / \mathrm{L}$ dry weight. After the optimization of hydrolysis parameters (data not shown), $78.4 \pm 0.6 \mathrm{~g} / \mathrm{L}$ reducing sugar was released to the hydrolysate, which contained $58.2 \pm 0.4 \mathrm{~g} / \mathrm{L}$ fructose and $12.7 \pm 0.6 \mathrm{~g} / \mathrm{L}$ glucose. In addition to reducing sugars, the hydrolysate contained $0.68 \pm 0.03 \mathrm{~g} / \mathrm{L}$ nitrogen and several kinds of

Table 1 Nutritional composition of Jerusalem artichoke tuber

\begin{tabular}{lll}
\hline Composition & Content & Reference \\
\hline Dry weight (g/100 g wet weight) & $20.4 \pm 0.5$ & This study \\
Total nitrogen (g/100 g dry weight) & $0.68 \pm 0.03$ & This study \\
Fructose ( $/ 100 \mathrm{~g}$ dry weight hydrolysate) & $58.2 \pm 0.4$ & This study \\
Glucose (g/100 g dry weight hydrolysate) & $12.7 \pm 0.6$ & This study \\
Total sugar (g/100 g dry weight) & $78.4 \pm 0.6$ & This study \\
Potassium (mg/100 g dry weight) & 2335 & {$[31]$} \\
Phosphorus (mg/100 g dry weight) & 389 & {$[31]$} \\
Magnesium (mg/100 g dry weight) & 189 & {$[31]$} \\
Calcium (mg/100 g of dry weight) & 186 & {$[31]$} \\
Sulfur (mg/100 g of dry weight) & 62 & {$[31]$} \\
\hline
\end{tabular}

mineral elements, such as potassium, phosphorus, magnesium and calcium [31].

\section{Optimization of the JAT medium for PMA and pullulan co-production}

To determine the optimal sugar concentration derived from the Jerusalem artichoke tuber hydrolysate on PMA production, the initial sugar concentrations from 60 to $120 \mathrm{~g} / \mathrm{L}$ were tested. As shown in Fig. 1, the increased sugar concentration was favorable for cell growth within the range of 60 to $120 \mathrm{~g} / \mathrm{L}$, the highest dry cell weight (DCW) concentration of $18.6 \pm 0.6 \mathrm{~g} / \mathrm{L}$ was achieved when the sugar concentration was $120 \mathrm{~g} / \mathrm{L}$, which was probably attributed to the high nitrogen content in the Jerusalem artichoke tuber hydrolysate. PMA production was improved when the initial sugar concentration increased from $60 \mathrm{~g} / \mathrm{L}$ to $100 \mathrm{~g} / \mathrm{L}$. The optimal concentration of initial sugar concentration for PMA production was $100 \mathrm{~g} / \mathrm{L}$ and PMA concentration reached the highest value $(31.2 \pm 0.4 \mathrm{~g} / \mathrm{L})$, further increasing the sugar concentration depressed PMA biosynthesis. Similar results were also observed on pullulan production by A.pullulans HA-4D, the optimal sugar concentration for pullulan production was $80 \mathrm{~g} / \mathrm{L}$. To obtain the highest yield of PMA, the initial sugar concentration of $100 \mathrm{~g} / \mathrm{L}$ derived from the Jerusalem artichoke tuber hydrolysate was used for the subsequent experiments.

In addition to monomeric sugar, the Jerusalem artichoke tuber hydrolysate also contains some mineral nutrients and vitamins, which might satisfy the nutrient demand of microorganisms for cell growth and product yield. Therefore, the standard PMA-producing medium might be simplified with the use of Jerusalem artichoke tuber hydrolysate. As shown in Table 2, several concentrations of the required nutrients, such as $\mathrm{NaNO}_{3}$,

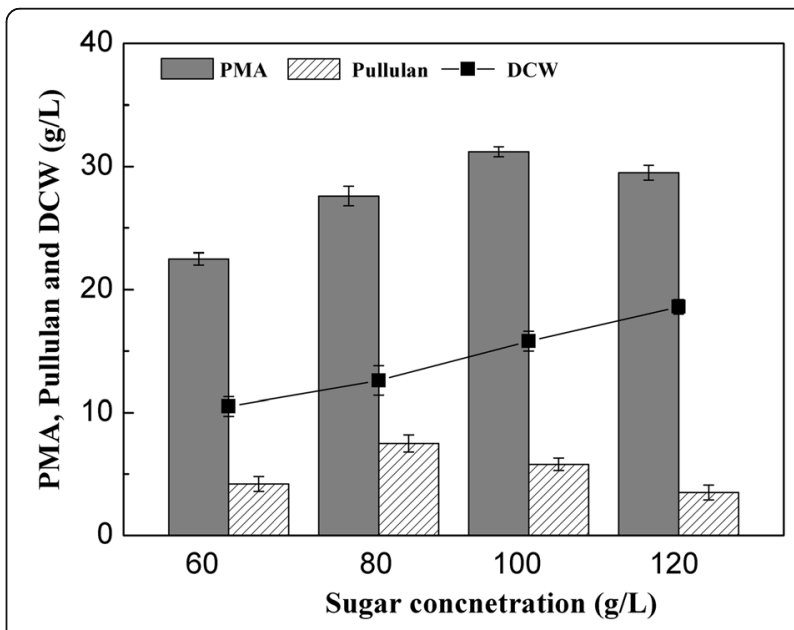

Fig. 1 Effect of initial sugar concentration derived from Jerusalem artichoke tuber hydrolysate on PMA and pullulan co-production in shake-flasks 
Table 2 Effects of different supplements on the co-production of PMA and pullulan by A.pullulans HA-4D in JAT fermentation medium. Shake flask fermentation was carried out at $25{ }^{\circ} \mathrm{C}$ and 200 rpm for 7 days

\begin{tabular}{lllll}
\hline Components & $\begin{array}{l}\text { Concentration } \\
(\mathrm{g} / \mathrm{L})\end{array}$ & $\begin{array}{l}\mathrm{PMA} \\
(\mathrm{g} / \mathrm{L})\end{array}$ & $\begin{array}{l}\text { Pullulan } \\
(\mathrm{g} / \mathrm{L})\end{array}$ & $\begin{array}{l}\mathrm{DCW} \\
(\mathrm{g} / \mathrm{L})\end{array}$ \\
\hline $\mathrm{NaNO}_{3}$ & 0 & $31.9 \pm 0.5$ & $5.3 \pm 0.4$ & $12.5 \pm 0.3$ \\
& 1 & $33.2 \pm 0.4^{*}$ & $6.3 \pm 0.4$ & $13.9 \pm 0.4^{*}$ \\
& 2 & $30.8 \pm 0.4$ & $5.8 \pm 0.4$ & $15.8 \pm 0.5^{* *}$ \\
$\mathrm{KH}_{2} \mathrm{PO}_{4}$ & 0 & $34.0 \pm 0.4$ & $6.1 \pm 0.5$ & $12.8 \pm 0.4$ \\
& 0.1 & $33.4 \pm 0.4$ & $6.3 \pm 0.4$ & $13.9 \pm 0.9$ \\
& 0.2 & $32.8 \pm 1.1$ & $6.6 \pm 0.5$ & $14.3 \pm 0.8$ \\
$\mathrm{MgSO}_{4}$ & 0 & $35.1 \pm 0.3$ & $5.8 \pm 0.5$ & $13.2 \pm 0.5$ \\
& 0.1 & $34.1 \pm 0.8$ & $6.1 \pm 0.3$ & $12.9 \pm 0.6$ \\
& 0.2 & $33.7 \pm 0.9$ & $6.7 \pm 0.3$ & $12.5 \pm 0.4$ \\
$\mathrm{KCl}^{2}$ & 0 & $36.3 \pm 0.5$ & $5.5 \pm 0.4$ & $11.9 \pm 0.2$ \\
& 0.5 & $35.1 \pm 0.5$ & $5.7 \pm 0.4$ & $12.5 \pm 0.4$ \\
& 1 & $34.6 \pm 0.9$ & $6.4 \pm 0.3$ & $12.9 \pm 0.8$ \\
$\mathrm{ZnSO}_{4}$ & 0 & $36.8 \pm 0.4$ & $6.0 \pm 0.3$ & $12.5 \pm 0.4$ \\
& 0.1 & $36.2 \pm 0.6$ & $5.5 \pm 0.4$ & $11.9 \pm 0.4$ \\
& 0.2 & $35.8 \pm 0.4$ & $5.1 \pm 0.5$ & $11.6 \pm 0.3$ \\
$\mathrm{CaCO}_{3}$ & 0 & $26.3 \pm 0.4$ & $9.7 \pm 0.6$ & $11.5 \pm 0.4$ \\
& 15 & $33.9 \pm 0.6^{* *}$ & $6.8 \pm 0.2^{* *}$ & $11.9 \pm 0.5$ \\
& 30 & $36.6 \pm 0.7^{* *}$ & $6.0 \pm 0.4^{* *}$ & $12.4 \pm 0.9$ \\
& & & &
\end{tabular}

${ }^{*} 0.01<P<0.05$

${ }^{* *} P<0.01$

$\mathrm{KH}_{2} \mathrm{PO}_{4}$ and $\mathrm{CaCO}_{3}$ were tested. The results showed that except for $\mathrm{NaNO}_{3}$ (optimal concentration of $1 \mathrm{~g} / \mathrm{L}$, $P<0.05$ ) and $\mathrm{CaCO}_{3}$ (optimal concentration of $30 \mathrm{~g} / \mathrm{L}$, $P<0.01$ ), no significant enhancements on PMA production were achieved when mineral nutrients were added to the medium containing the Jerusalem artichoke tuber hydrolysate. Meanwhile, pullulan yield was significantly decreased with the addition of $\mathrm{CaCO}_{3}(P<0.01)$ and cell growth was enhanced with the addition of $\mathrm{NaNO}_{3}$ $(P<0.05)$. Therefore, when Jerusalem artichoke tuber hydrolysate was employed as the carbon source for PMA production, no extra components, except for $\mathrm{NaNO}_{3}$ and $\mathrm{CaCO}_{3}$, were added to the medium, which would further decrease the cost of PMA fermentation.

\section{Analysis of the co-fermentation products}

In addition to PMA, we found that A.pullulans HA-4D also produced an unknown exopolysaccharide as a byproduct. As shown in Fig. 2a, the exopolysaccharide was pigment-free and precipitated on the upper layer of the culture broth. A.pullulans is a biotechnologically important fungus due to its high yield of the commercial polysaccharide, pullulan. To verify if the exopolysaccharide produced by A.pullulans HA-4D is also pullulan, the purified exopolysaccharide was subjected to structural characterization using FT-IR and NMR spectra. The absorption band in the FT-IR spectrum (Additional file 1: Figure S1a) at $3394 \mathrm{~cm}^{-1}$ and $2928 \mathrm{~cm}^{-1}$ were characteristic of $\mathrm{O}-\mathrm{H}$ stretching and $\mathrm{C}-\mathrm{H}$ stretching, respectively. The characteristic signals appeared at 1637, 1420, 1152 and $1020 \mathrm{~cm}^{-1}$ were due to $\mathrm{O}-\mathrm{C}-\mathrm{O}$ stretching, $\mathrm{C}-\mathrm{O}-\mathrm{H}$ bending, C-O-C stretching and $\mathrm{C}-\mathrm{O}$ stretching, respectively [25]. Furthermore, the signals arrived in the ${ }^{1} \mathrm{H}$ NMR spectrum (Additional file 1: Figure S1b) between 4 and $5.5 \mathrm{ppm}$ infers proton carrying carbon atoms attached to an electronegative atom, signals at $1.0 \mathrm{ppm}$ was due to 6-deoxy-D-altrose present in the pullulan [25]. ${ }^{13} \mathrm{C}-\mathrm{NMR}$ for the purified exopolysaccharide was shown in Additional file 1: Figure S1c, the anomeric carbon region shows three signals corresponding to $\alpha-(1 \rightarrow 4)$ $(101.8,101.1 \mathrm{ppm})$ and $\alpha-(1 \rightarrow 6)(99.2 \mathrm{ppm})$ linkages, splitting of C-6 (60.7, $61.3 \mathrm{ppm})$ and C-4 (80.4, $81.2 \mathrm{ppm})$ were due to $\mathrm{C}$-1 of $(1 \rightarrow 4)$ linked glucose unit, the signal resonance at $67.4 \mathrm{ppm}$ corresponds to C-6 of the 1,6linked $\alpha$-D-glucose [32]. Based on the above results, the exopolysaccharide produced by A.pullulans HA4D was confirmed to be pullulan.

After the removal of pullulan, the fermentation broth was subjected to acid hydrolysis and PMA was hydrolyzed to malic acid. As shown in Fig. 2b, the dominant component of the fermentation broth hydrolysate was malic acid, only a few impurities existed in the fermentation broth. The kinetics of the acid hydrolysis of PMA had been investigated previously, a very high recovery rate $(84 \sim 99 \%)$ of malic acid from PMA was easily obtained by a simple acid hydrolysis method [2, 10]. A.pullulans HA-4D could produce a high amount of PMA under suitable conditions [24], thus we think that A.pullulans HA-4D can be a good candidate for high malic acid production with high purity, and the co-produced pullulan could enrich the diversity of the products and improve the economical-feasibility of the fermentation process.

\section{Fed-batch fermentation for the co-production of PMA and pullulan}

To scale up PMA and pullulan co-production from Jerusalem artichoke tubers, $5 \mathrm{~L}$ fermentation was carried out with the JAT medium. Our previous study demonstrated that fed-batch fermentation favored the highlevel accumulation of PMA by A.pullulans HA-4D [24], thus fed-batch fermentation with a continuous feeding strategy was carried out in this study. The time course of the PMA, pullulan, biomass and residual sugar concentration was shown in Fig. 3a. After $168 \mathrm{~h}$ of fermentation, the final PMA, pullulan and biomass concentration achieved $114.4 \pm 2.4 \mathrm{~g} / \mathrm{L}, 14.3 \pm 1.5 \mathrm{~g} / \mathrm{L}$ and $23.4 \pm 1.1 \mathrm{~g} / \mathrm{L}$, respectively. The PMA and pullulan yield on sugar was $0.74 \mathrm{~g} / \mathrm{g}$ and $0.09 \mathrm{~g} / \mathrm{g}$, respectively. As a control, PMA and 


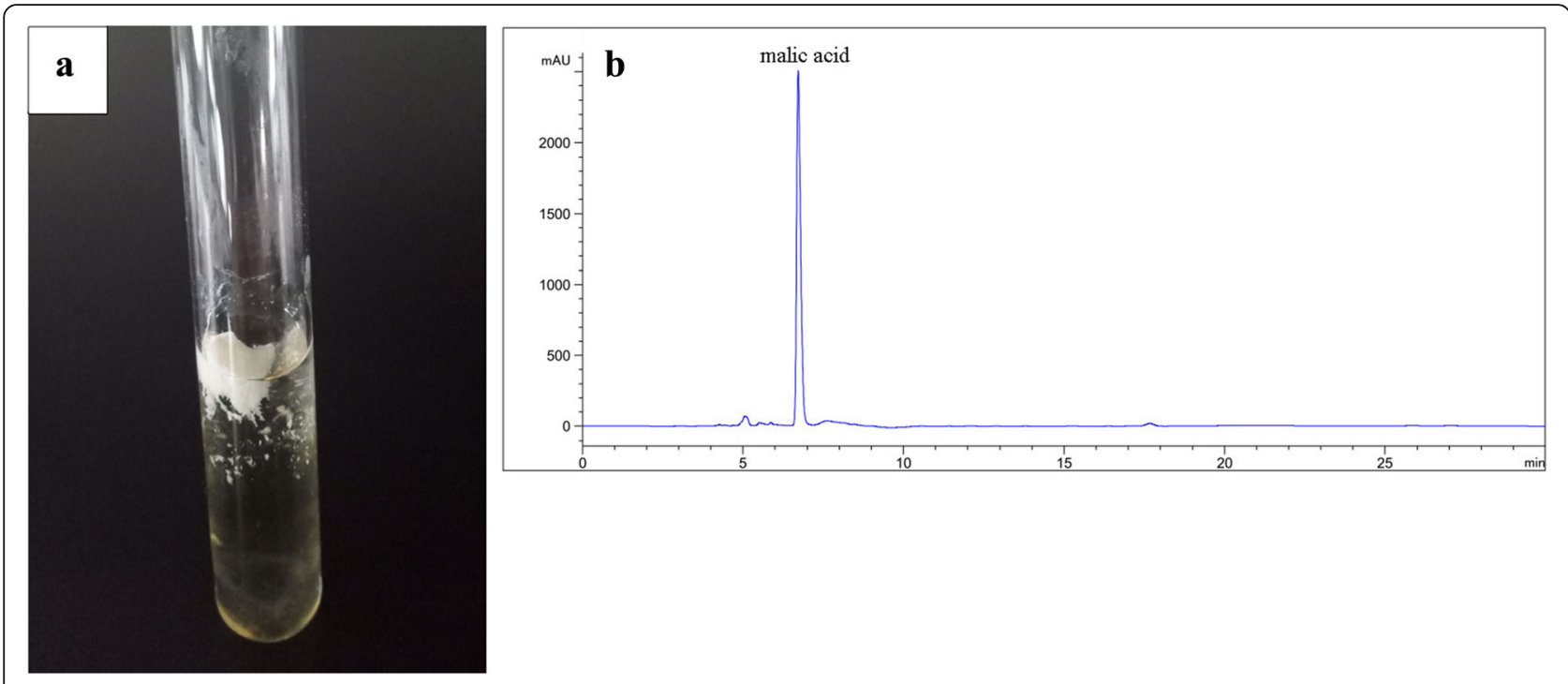

Fig. 2 Precipitation of exopolysaccharide with the addition of ethanol (a) and HPLC analysis of the supernatant after the removal of exopolysaccharide (b)

pullulan co-production using GM medium was also carried out (data not shown), the resulting concentrations of PMA, pullulan and biomass reached $96.2 \pm 1.8 \mathrm{~g} / \mathrm{L}, 20.8 \pm$ $1.3 \mathrm{~g} / \mathrm{L}$ and $20.2 \pm 0.8 \mathrm{~g} / \mathrm{L}$, respectively. Meanwhile, PMA and pullulan yield on sugar with GM medium was $0.62 \mathrm{~g} /$
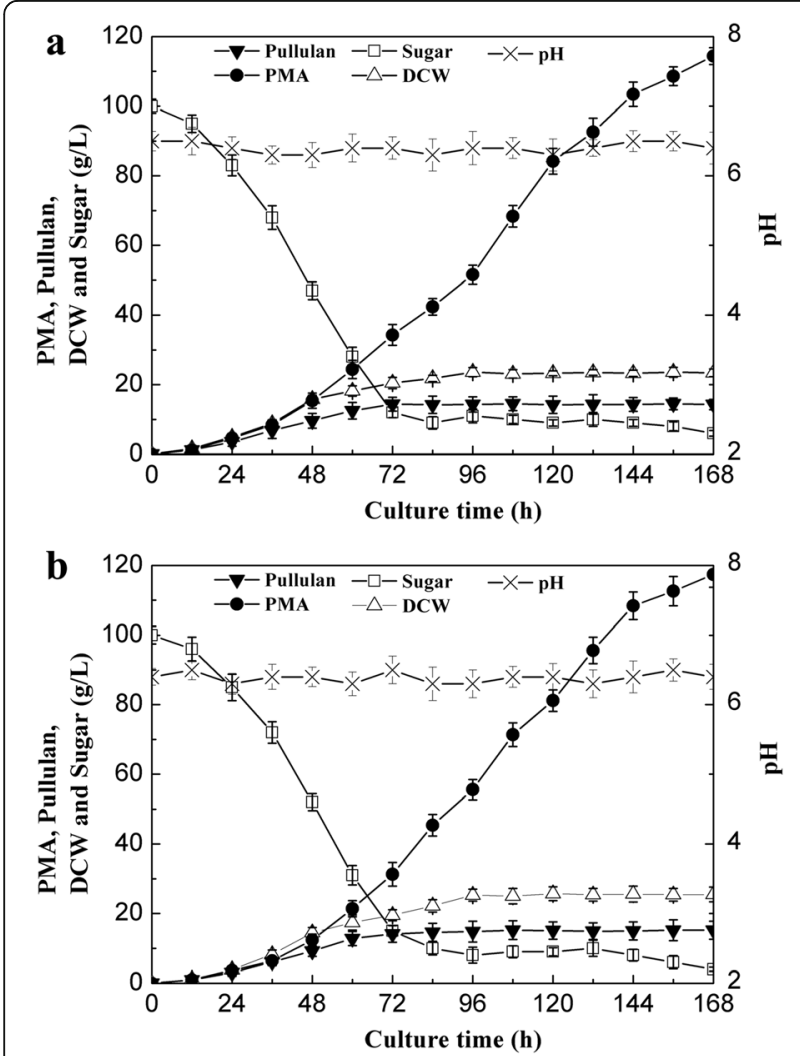

Fig. 3 PMA and pullulan co-production with JAT medium in fed-batch fermentation by A.pulluans HA-4D. a $5 \mathrm{~L}$ fermentor; (b) $1 \mathrm{t}$ fermentor $\mathrm{g}$ and $0.14 \mathrm{~g} / \mathrm{g}$, respectively. The concentration of PMA and pullulan obtained with JAT medium was $18.9 \%$ higher and $31.3 \%$ lower, respectively, compared with those with GM medium, this result indicated that JAT medium was beneficial for PMA biosynthesis but unfavorable for pullulan production. On the other hand, the better cell growth obtained from JAT medium might be attributed to the abundant nitrogen content of the Jerusalem artichoke tubers.

Furthermore, to examine the feasibility of large-scale PMA and pulluan co-production with JAT medium, fedbatch fermentation was scaled up to a $1 \mathrm{t}$ fermentor. As shown in Fig. 3b, the pullulan and PMA production was comparable to that of a $5 \mathrm{~L}$ fermentor. The final PMA and pullulan concentration reached $117.5 \pm 3.7 \mathrm{~g} / \mathrm{L}$ and $15.2 \pm 2.6 \mathrm{~g} / \mathrm{L}$, respectively, thereby suggesting that PMA and pullulan co-production from Jerusalem artichoke tuber is a promising route for industrial purpose. The production levels of PMA and pullulan by different strains were summarized in Table 3 [13, 19, 20, 33-36]. Compared with the co-production of PMA and pullulan by other strains, the PMA and pullulan levels in this work were superior to other reports in literature, but inferior to the highest level of the individual production of PMA or pullulan. Therefore, the co-production system for PMA and pullulan in this study was practical and economical. Through this co-production system, the cost of raw materials was significantly decreased, and a valuable exopolysaccharide was co-produced to improve the economics of the system.

Enzyme activity in the biosynthesis of PMA and pullulan Pullulan and PMA can be produced simultaneously due to their tightly interrelated metabolic pathway, the 
Table 3 Comparison of PMA and pullulan production by different strains in different fermentation processes

\begin{tabular}{|c|c|c|c|c|c|}
\hline Strain & Substrate & $\begin{array}{l}\text { PMA } \\
(g / L)\end{array}$ & $\begin{array}{l}\text { Pullulan } \\
\text { (g/L) }\end{array}$ & $\begin{array}{l}\text { Time } \\
\text { (h) }\end{array}$ & Reference \\
\hline A.pullulans RSU7 & glucose & 8.9 & 9.8 & 168 & [20] \\
\hline \multirow{2}{*}{$\begin{array}{l}\text { A.pullulans } \\
\text { CCTCC M2012223 }\end{array}$} & glucose & 46.5 & 28.8 & 60 & [19] \\
\hline & HSP & 57.5 & ND & 156 & [13] \\
\hline $\begin{array}{l}\text { A.pullulans var. } \\
\text { pullulans MCW }\end{array}$ & glucose & 152.5 & ND & 120 & [33] \\
\hline A.pullulans ipe-1 & glucose & 60 & ND & 72 & [34] \\
\hline A.pullulans Y68 & glucose & ND & 59 & 60 & {$[35]$} \\
\hline $\begin{array}{l}\text { A.pullulans var. } \\
\text { melanogenium P16 }\end{array}$ & sucrose & ND & 67.4 & 132 & {$[36]$} \\
\hline \multirow[t]{2}{*}{ A.pullulans HA-4D } & glucose & 96.2 & 20.8 & 168 & This study \\
\hline & HJAT & 117.5 & 15.2 & 168 & \\
\hline
\end{tabular}

HSP Hydrolysate of sweet potato, HJAT Hydrolysate of Jerusalem artichoke tuber, ND No data

proposed metabolism pathways of PMA and pullulan are shown in Fig. 4. Pyruvate carboxylase (PYC; EC 6.4.1.1) and malate dehydrogenase (MDH; EC 1.1.1.37) are the key enzymes in the biosynthetic pathway of malic acid, $\alpha$-phosphoglucose mutase (PGM; EC 5.4.2.2), UDPglucose pyrophosphorylase (UDPG; EC 2.7.7.9) and glucosyltransferase (FKS; EC 2.4.1.34) are generally regarded as key enzymes involved in pullulan synthesis [37]. To demonstrate the effect of the Jerusalem artichoke tuber hydrolysate on the intracellular carbon flux, the key enzymes involved in the biosynthetic pathway of PMA and pullulan were assayed. Cells at early stage $(40 \mathrm{~h})$ and later stage $(100 \mathrm{~h})$ of fermentation process were collected to analyze the enzyme activity. As shown in Table 4, the PYC activity was significantly enhanced at both phases $(40 \mathrm{~h}: P<0.01 ; 100 \mathrm{~h}: P<0.05)$ when JAT medium was used. Higher MDH activity was also observed when A.pullulans HA-4D was grown on JAT medium than on GM medium. By contrast, the activity of PGM, UDPG and FKS was not significantly affected. PYC and MDH are the key enzymes of malic acid biosynthesis pathway, thus the improved activities of PYC and $\mathrm{MDH}$ were beneficial for malic acid production. Jerusalem artichoke tuber contains several vitamins, including vitamin $A, B_{1}, B_{2}, B_{3}, B_{6}, B_{7}$ and $C$ [38]. Biotin (vitamin $B_{7}$ ) is the key cofactor for PYC, the sufficient biotin available in the Jerusalem artichoke tuber may stimulate PYC activity so that PMA production was enhanced. Similar results were reported by other researchers. For example, Zou et al. [39] investigated the effects of cofactor on PMA production, and they found that PMA concentration was increased from $14.3 \mathrm{~g} / \mathrm{L}$ to $23.1 \mathrm{~g} / \mathrm{L}$ with the addition of $70 \mathrm{mg} / \mathrm{L}$ biotin. Therefore, the improved PYC and MDH activity might cause the global metabolic flux redistributions, thus the reductive pathway of malic acid would be strengthened by the use of JAT medium. Consequently, PMA production was enhanced.

\section{Discussion}

Jerusalem artichoke tuber is rich in carbohydrates, of which $70-90 \%(\mathrm{w} / \mathrm{w})$ is inulin [14], and inulin can be easily hydrolyzed to monomeric sugars (fructose and glucose) for microbial fermentation. Enzymatic and acidic hydrolysis are the most commonly used pretreatment methods for Jerusalem artichoke tuber. Commercial inulinase hydrolysis is usually carried out at $55{ }^{\circ} \mathrm{C}$ for $12 \mathrm{~h}$, with an enzyme loading of $2.0 \mathrm{U} / \mathrm{g}$ substrate [17]. To reduce the cost of purchasing commercial inulinase, the mixed culture of two different strains is often employed. For example, Shin et al. [30] performed pullulan production from Jerusalem artichoke using a mixed culture of A.pullulans and Kluyveromyces fragilis. K.fragilis was introduced as an inulinase producer to accelerate the hydrolysis of inulin into fructose, and A.pullulans served as

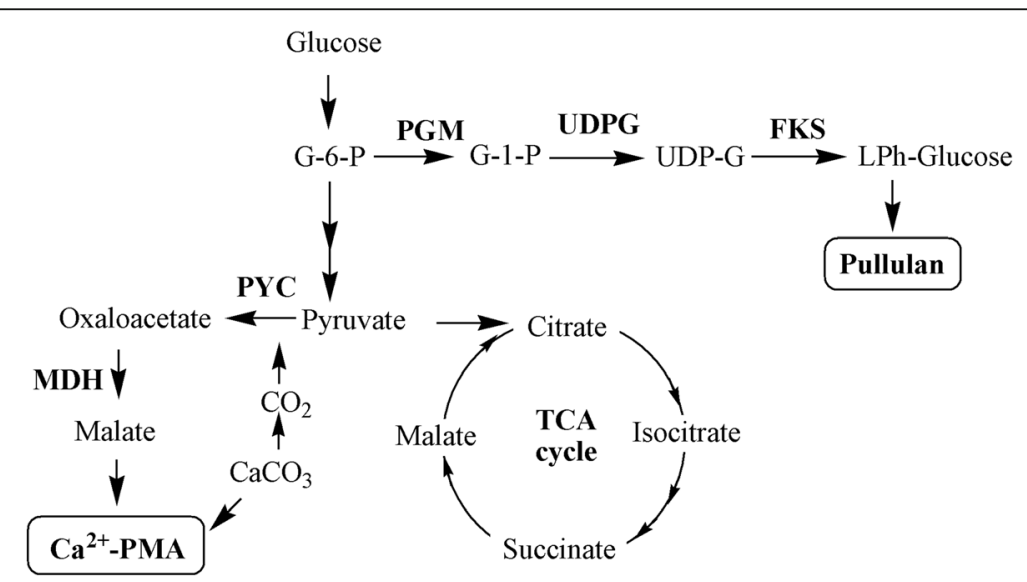

Fig. 4 The proposed pathway of PMA and pullulan metabolism in A.pullulans 
Table 4 Activity of key enzymes involved in PMA and pullulan biosynthesis when A.pullulans HA-4D was grown in JAT medium or GM medium. PYC: pyruvate carboxylase; MDH: malate dehydrogenase; PGM: a-phosphoglucose mutase; UDPG: UDP-glucose pyrophosphorylase; FKS: glucosyltransferase

\begin{tabular}{|c|c|c|c|c|c|c|}
\hline \multirow[t]{2}{*}{ Time } & \multirow[t]{2}{*}{ Medium } & \multicolumn{5}{|c|}{ Specific enzyme activities (U/mg protein) } \\
\hline & & PYC & $\mathrm{MDH}$ & PGM & UDPG & FKS \\
\hline \multirow[t]{2}{*}{$40 \mathrm{~h}$} & GM & $0.18 \pm 0.03$ & $4.55 \pm 0.44$ & $(7.86 \pm 0.40) \times 10^{-3}$ & $(56.89 \pm 5.88) \times 10^{-3}$ & $0.79 \pm 0.05$ \\
\hline & JAT & $0.31 \pm 0.02^{* *}$ & $5.37 \pm 0.30$ & $(8.25 \pm 0.19) \times 10^{-3}$ & $(53.41 \pm 3.95) \times 10^{-3}$ & $0.85 \pm 0.03$ \\
\hline \multirow[t]{2}{*}{$100 \mathrm{~h}$} & GM & $0.10 \pm 0.02$ & $2.52 \pm 0.43$ & $(6.29 \pm 0.37) \times 10^{-3}$ & $(25.51 \pm 3.35) \times 10^{-3}$ & $0.68 \pm 0.04$ \\
\hline & JAT & $0.19 \pm 0.03^{*}$ & $2.88 \pm 0.22$ & $(5.86 \pm 0.42) \times 10^{-3}$ & $(27.86 \pm 4.09) \times 10^{-3}$ & $0.65 \pm 0.05$ \\
\hline
\end{tabular}

${ }^{*} 0.01<P<0.05$

${ }^{* *} P<0.01$

pullulan producer, the maximum pullulan production reached $15.5 \mathrm{~g} / \mathrm{L}$ with this mixed culture system. In addition to enzymatic hydrolysis, acid hydrolysis is also often employed for the pretreatment of Jerusalem artichoke tuber. Yu et al. [18] found that among sulphuric, nitric and hydrochloric acids, sulphuric acid was the optimal acid for the hydrolysis of Jerusalem artichoke tubers. Acid hydrolysis is usually carried out with $0.2 \sim 5 \% \mathrm{H}_{2} \mathrm{SO}_{4}$ at a liquidto-solid ratio of $10: 1$ at $100{ }^{\circ} \mathrm{C}$ for $1 \mathrm{~h}$. In the present study, the yield of reducing sugars was $78.4 \mathrm{~g}$ sugar/100 $\mathrm{g}$ dry Jerusalem artichoke tuber, thus sulphuric acid hydrolysis is a better route compared to the costly and lengthy enzymatic hydrolysis for the saccharification of Jerusalem artichoke tubers.

Aside from fructose and glucose as the major components, the hydrolysate of Jerusalem artichoke tuber also contain some other nutrients including protein, mineral contents and vitamins [15]. Therefore, the medium for PMA and pullulan co-production was significantly simplified with the use of Jerusalem artichoke tuber hydrolysate, which is a significant advantage in terms of decreasing the cost and increasing the efficiency of PMA and pulluan co-production. Similar results were reported for the fermentation of other bioproducts. For example, Gunnarsson et al. [16] found that when Jerusalem artichoke tuber hydrolysate was employed for succinic acid production, the addition of yeast extract and other nutrients was not strictly required, and $49.7 \mathrm{~g} / \mathrm{L}$ succinic acid was produced from the Jerusalem artichoke tuber hydrolysate without additional media supplementation. Gao et al. [40] conducted single-cell protein fermentation by a marine yeast Cryptococcus aureus G7a, $53.0 \mathrm{~g}$ of crude protein per $100 \mathrm{~g}$ of cell dry weight was obtained from the medium consisting of Jerusalem artichoke extract only supplemented with hydrolysate of soybean meal.

In addition to the hydrolysate of Jerusalem artichoke tuber, the addition of $\mathrm{CaCO}_{3}$ to the medium was indispensible for the biosynthesis of PMA. First, the presence of $\mathrm{CaCO}_{3}$ can maintain the $\mathrm{pH}$ between 6.0 and 6.5, which is quite important for PMA production because a low $\mathrm{pH}$ may result in the degradation of PMA $(\mathrm{pH}<5.0)$
[41]. Besides, a low pH may also induce the formation of by-product (e.g., extracellular polysaccharides) and chlamydospore by some strains of Aureobasidium spp. [42], which is undesirable in PMA production. Another reason for this is the significant role of $\mathrm{CaCO}_{3}$ in the biosynthesis of malic acid. Previous studies demonstrated that malic acid was synthesized either via the carboxylation of pyruvate and subsequent reduction of oxaloacetate (the reductive pathway) or the tricarboxylic acid cycle (the oxidative pathway) [43]. Malic acid synthesis via the reductive pathway provides a maximal theoretical yield of $2 \mathrm{~mol}$ malic acid per mol of glucose [8]. The presence of $\mathrm{CaCO}_{3}$ induced the switch of malic acid generation to the reductive pathway [43], thereby providing massive amounts of malic acid as the precursor for PMA biosynthesis.

\section{Conclusions}

In this study, an economical co-production system for PMA and pullulan from Jerusalem artichoke was developed. The medium for PMA and pullulan co-production was significantly simplified when Jerusalem artichoke tubers were used. With the simplified medium, the production of PMA and pullulan in $1 \mathrm{t}$ fermentor reached $117.5 \mathrm{~g} /$ $\mathrm{L}$ and $15.2 \mathrm{~g} / \mathrm{L}$, respectively. Meanwhile, PMA production was obviously stimulated, which would be associated with the improved activity of pyruvate carboxylase and malate dehydrogenas. This study demonstrated the great potential of Jerusalem artichoke for the economical co-production of PMA and pullulan at industrial scale.

\section{Additional files}

Additional file 1: Figure S1. Structural characterization of the exopolysaccharide with FT-IR spectrum (a), ${ }^{1} \mathrm{H}-\mathrm{NMR}$ spectrum (b) and ${ }^{13}$ C-NMR spectrum (c). (DOCX $\left.275 \mathrm{~kb}\right)$

Additional file 2: Raw data used for the production of Additional file 1: Figure S1a, Table 2 and Table 4. (XLSX 186 kb)

\section{Abbreviations}

DCW: Dry cell weight; FKS: Glucosyltransferase; FT-IR: Fourier transform infrared spectroscopy; G-1-P: Glucose-1-phosphate; G-6-P: Glucose-6-phosphate; GM medium: The standard PMA production medium; JAT medium: The optimized 
fermentation medium; LPh: Phospholipds intermediate; MDH: Malate dehydrogenase; NMR: Nuclear magnetic resonance spectra; PGM: aphosphoglucose mutase; PMA: Poly(L-malic acid); PYC: Pyruvate carboxylase; UDPG: UDP-glucose pyrophosphorylase; UDP-G: Uridine 5'-diphosphate glucose

\section{Acknowledgement}

We thank Baimai Co., Ltd. (Huai'an, PR China) for providing $1 \mathrm{t}$ jar fermentor.

\section{Funding}

This work was supported by the Natural Science Foundation of China (No.21406083 and 31600047), the Natural Science Foundation of Jiangsu Province (No.BK20150412), Huai'an Municipal Science and Technology Support Program (No.HAG2015037) and Opening Fund of Jiangsu Province Engineering Laboratory for Biomass Conversion and Process Integration (Huaiyin Institute of Technology, JPELBCPI2015001)

\section{Availability of data and materials}

All the data supporting our conclusions are included within the manuscript and its additional files. The data used for the production of Additional file 1 Figure S1a, Table 2 and Table 4 could be found in the Additional file 2 .

\section{Authors' contributions}

JX conceived the study; JX, JXX and XYL carried out the experiments; JMX and XFW provided project supervision, helped with statistical design and analysis; JX wrote the paper; JX and XQL reviewed the paper. All authors read and approved the final manuscript.

\section{Competing interests}

The authors declare that they have no competing interests.

\section{Consent for publication}

Not applicable.

\section{Ethics approval and consent to participate}

Not applicable.

\section{Author details}

'Jiangsu Key Laboratory for Biomass-Based Energy and Enzyme Technology, Jiangsu Collaborative Innovation Center of Regional Modern Agriculture and Environmental Protection, College of Chemistry and Chemical Engineering, Huaiyin Normal University, Huai'an 223300, China. ${ }^{2}$ Jiangsu Province Engineering Laboratory for Biomass Conversion and Process Integration, Huaiyin Institute of Technology, Huai'an 223300, China.

\section{Received: 11 October 2016 Accepted: 17 February 2017}

\section{Published online: 23 February 2017}

\section{References}

1. Ding H, Portilla-Arias J, Patil R, Black KL, Ljubimova JY, Holler E. The optimization of polymalic acid peptide copolymers for endosomolytic drug delivery. Biomaterials. 2011;32:5269-78.

2. Zou X, Zhou Y, Yang ST. Production of polymalic acid and malic acid by Aureobasidium pullulans fermentation and acid hydrolysis. Biotechnol Bioeng. 2013;110:2105-13.

3. Ding H, Ljubimova JY, Holler E, Black KL. Poly(beta-malic acid) with pendant leu-leu-leu tripeptide for effective cytoplasmic drug delivery. PCT/US2009/ 040252,WO/2009/126913

4. Black KL, Ljubimova JY, Ljubimov AV, Holler E. Polymalic acid based nanoconjugates for imaging. PCT/US2012/032573,WO/2012/139030.

5. Ding $H$, Inoue $S$, Ljubimov AV, Patil R, Portilla-Arias J, Hu J, Konda B, Wawrowsky KA, Fujita M, Karabalin N, Sasaki T, Black KL, Holler E, Ljubimova JY. Inhibition of brain tumor growth by intravenous poly( $\beta$-L-malic acid) nanobioconjugate with pH-dependent drug release. PNAS. 2010;107:18143-8.

6. Goldberg I, Rokem JS, Pines O. Organic acids: Old metabolites, new themes. J Chem Technol Biotechnol. 2006;81:1601-11.

7. Battat E, Peleg Y, Bercovitz A, Rokem JS, Goldberg I. Optimization of L-malic acid production by Aspergillus flavus in a stirred fermentor. Biotechnol Bioeng 1991;37:1108-16

8. Zhang X, Wang X, Shanmugam KT, Ingram LO. L-malate production by metabolically engineered Escherichia coli. Appl Environ Microbiol. 2011;77:427-34.
9. Hedayati MT, Pasqualotto AC, Warn PA, Bowyer P, Denning DW. Aspergillus flavus: Human pathogen, allergen and mycotoxin producer. Microbiology. 2007;153:1677-92.

10. Zhang HL, Cai J, Dong JQ, Zhang DP, Huang L, Xu ZN, Cen PL. High-level production of poly( $\beta$-L-malic acid) with a new isolated Aureobasidium pullulans strain. Appl Microbiol Biotechnol. 2011;92:295-303.

11. Leathers TD, Manitchotpisit P. Production of poly ( $\beta$ - $L$-malic acid) (PMA) from agricultural biomass substrates by Aureobasidium pullulans. Biotechnol Lett. 2013;35:83-9.

12. Zou X, Wang YK, Tu GW, Zan ZQ, Wu XY. Adaptation and transcriptome analysis of Aureobasidium pullulans in corncob hydrolysate for increased inhibitor tolerance to malic acid production. Plos One. 2015;10:e0121416.

13. Zan ZQ, Zou X. Efficient production of polymalic acid from raw sweet potato hydrolysate with immobilized cells of Aureobasidium pullulans CCTCC M2012223 in aerobic fibrous bed bioreactor. J Chem Technol Biotechnol. 2013:88:1822-7.

14. Bovell-Benjamin AC. Sweet potato: a review of its past, present, and future role in human nutrition. Adv Food Nutr Res. 2007:52:1-59.

15. Gunnarsson IB, Svensson SE, Johansson E, Karakashev D, Angelidaki I. Potential of Jerusalem artichoke (Helianthus tuberosus L.) as a biorefinery crop. Ind Crops Prod. 2014;56:231-40.

16. Gunnarsson IB, Karakashev D, Angelidaki I. Succinic acid production by fermentation of Jerusalem artichoke tuber hydrolysate with Actinobacillus succinogenes 130Z. Ind Crops Prod. 2014;62:125-9.

17. Sun HL, Wang XD, Dai JY, Xiu ZL. Microbial production of 2,3-butanediol from Jerusalem artichoke tubers by Klebsiella pneumoniae. Appl Microbiol Biotechnol. 2009:82:847-52.

18. Yu XJ, Liu JH, Sun J, Zheng JY, Zhang YJ, Wang Z. Docosahexaenoic acid production from the acidic hydrolysate of Jerusalem artichoke by an efficient sugar-utilizing Aurantiochytrium sp. YLH70. Ind Crops Prod. 2016;83:372-8.

19. Tu GW, Wang YK, Ji YC, Zou X. The effect of Tween 80 on the polymalic acid and pullulan production by Aureobasidium pullulans CCTCC M2012223. World J Microbiol Biotechnol. 2015:31:219-26.

20. Manitchotpisit P, Skory CD, Peterson SW, Price NPJ, Vermillion KE, Leathers TD. Poly $(\beta$-L-malic acid) production by diverse phylogenetic clades of Aureobasidium pullulans. J Ind Microbiol Biotechnol. 2014;39:125-32.

21. Sutherland LW. Novel and established application of microbial polysaccharide. Trends Biotechnol. 1998;16:41-6.

22. Yuen S. Pullulan and its applications. Process Biochem. 1974:9:7-9.

23. Kimoto T, Shibuya T, Shiobara S. Safety studies of a novel starch, pullulan: chronic toxicity in rats and bacterial mutagenicity. Food Chem Toxicol. 1997:35:323-9.

24. Xia J, Xu JX, Hu L, Liu XY. Enhanced poly(L-malic acid) production from pretreated cane molasses by Aureobasidium pullulans in fed-batch fermentation. Prep Biochem Biotechnol. 2016;46:798-802.

25. Sugumaran KR, Gowthami E, Swathi B, Elakkiya S, Srivastava SN, Ravikumar R, Gowdhaman D, Ponnusami V. Production of pullulan by Aureobasidium pullulans from Asian palm kernel: A novel substrate. Carbohyd Polym. 2013:92:697-703.

26. Duan $X$, Chi Z, Wang L, Wang X. Influence of different sugars on pullulan production and activities of a-phosphoglucose mutase, UDPG-pyrophosphorylase and glucosyltransferase involved in pullulan synthesis in Aureobasidium pullulans Y68. Carbohyd Polym. 2008;73:587-93.

27. Teague WM, Henney HR. Purification and Properties of Cytoplasmic and Mitochondrial Malate Dehydrogenases of Physarum polycephalum. J Bacteriol. 1973;116:673-84

28. Yin X, Madzak C, Du G, Zhou J, Chen J. Enhanced alpha-ketoglutaric acid production in Yarrowia lipolytica WSH-ZO6 by regulation of the pyruvate carboxylation pathway. Appl Microbiol Biotechnol. 2012;96:1527-37.

29. Miller GL. Use of dinitrosalicylic acid regent for determination of reducing sugar. Anal Chem. 1959;31:426-8.

30. Shin YC, Kim YH, Lee HS, Cho SJ, Byun SM. Production of exopolysaccharide pullulan from inulin by a mixed culture of Aureobasidium pullulans and Kluyveromyces fragilis. Biotechnol Bioeng. 1989:33:129-33.

31. Harmankaya M, Al Juhaimi F, Ozcan MM. Mineral contents of Jerusalem artichoke (Helianthus tuberosus L.) growing wild in Tuekey. Anal Lett. 2012; 45:2269-75

32. Youssef $F$, Roukas T, Biliaderis CG. Pullulan production by a non-pigmented strain of Aureobasidium pullulans using batch and fed-batch culture. Process Biochem. 1999:34:355-66.

33. Wang YK, Chi Z, Zhou HX, Liu GL, Chi ZM. Enhanced production of $\mathrm{Ca}^{2}$ ${ }^{+}$-polymalate (PMA) with high molecular mass by Aureobasidium pullulans var. pullulans MCW. Microb Cell Fact. 2015;14:115. 
34. Cao WF, Luo JQ, Zhao J, Qiao CS, Ding LH, Qi BK, Su Y, Wan YH. Intensification of $\beta$-poly(L-malic acid) production by Aureobasidium pullulans ipe-1 in the late exponential growth phase. J Ind Microbiol Biotechnol. 2012;39:1073-80.

35. Chi ZM, Zhao SZ. Optimization of medium and cultivation conditions for pullulan production by a new pullulan-producing yeast. Enzyme Microb Technol. 2003;33:206-11.

36. Ma ZC, Fu WJ, Liu GL, Wang ZP, Chi ZM. High-level pullulan production by Aureobasidium pullulans var. melanogenium P16 isolated from mangrove system. Appl Microbiol Biotechnol. 2014;98:4865-73.

37. Cheng KC, Demirci A, Catchmark JM. Pullulan: biosynthesis, production, and applications. Appl Microbiol Biotechnol. 2011;92:29-44.

38. Nsabimana C, Jiang B. The chemical composition of some garden Dahlia tubers. Br Food J. 2011;113:1081-93.

39. Zou X, Tu GW, Zan ZQ. Cofactor and $\mathrm{CO}_{2}$ donor regulation involved in reductive routes for polymalic acid production by Aureobasidium pullulans CCTCC M2012223. Bioproc Biosyst Eng. 2014;37:2131-6.

40. Gao LM, Chi ZM, Sheng J, Ni XM, Wang L. Single-cell protein production from Jerusalem artichoke extract by a recently isolated marine yeast Cryptococcus ureus G7a and its nutritive analysis. Appl Microbiol Biotechnol. 2007;77:825-32

41. Holler E, Angerer B, Achhammer G, Miller S, Windisch C. Biological and biosynthetic properties of poly-L-malate. FEMS Microbiol Rev. 1992:103:109-18.

42. Li BX, Zhang N, Peng Q, Yin T, Guan FF, Wang GL, Li Y. Production of pigment-free pullulan by swollen cell in Aureobasidium pullulans NG which cell differentiation was affected by $\mathrm{pH}$ and nutrition. Appl Microbiol Biotechnol. 2009;84:293-300

43. Lee BS, Maurer T, Kalbitzer HR, Holler E. $\beta$-poly-(L-malate) production by Physarum polycephalum, ${ }^{13} \mathrm{C}$ Nuclear magnetic resonance studies. Appl Microbiol Biotechnol. 1999;52:415-20.

\section{Submit your next manuscript to BioMed Central and we will help you at every step:}

- We accept pre-submission inquiries

- Our selector tool helps you to find the most relevant journal

- We provide round the clock customer support

- Convenient online submission

- Thorough peer review

- Inclusion in PubMed and all major indexing services

- Maximum visibility for your research

Submit your manuscript at www.biomedcentral.com/submit 